\title{
Activation of fibroblast-like synoviocytes derived from rheumatoid arthritis via lysophosphatidic acid-lysophosphatidic acid receptor 1 cascade
}

\author{
Yoshishige Miyabe1, Chie Miyabe ${ }^{1,2}$, Yoshiko Iwai $^{3}$, Waka Yokoyama' ${ }^{1}$, Chiyoko Sekine ${ }^{4}$, Kazutaka Sugimoto ${ }^{5}$, \\ Masayoshi Harigai ${ }^{1,6}$, Masayuki Miyasaka ${ }^{7}$, Nobuyuki Miyasaka ${ }^{1}$ and Toshihiro Nanki ${ }^{1,4,6^{*}}$
}

\begin{abstract}
Introduction: Lysophosphatidic acid (LPA) is a bioactive lipid that binds to $G$ protein-coupled receptors ( $\left.\mathrm{LPA}_{1-6}\right)$. Recently, we reported that abrogation of LPA receptor $1\left(\mathrm{LPA}_{1}\right)$ ameliorated murine collagen-induced arthritis, probably via inhibition of inflammatory cell migration, Th17 differentiation and osteoclastogenesis. In this study, we examined the importance of the LPA-LPA, axis in cell proliferation, cytokine/chemokine production and lymphocyte transmigration in fibroblast-like synoviocytes (FLSs) obtained from the synovial tissues of rheumatoid arthritis (RA) patients.
\end{abstract}

Methods: FLSs were prepared from synovial tissues of RA patients. Expression of $\mathrm{LPA}_{1-6}$ was examined by quantitative real-time RT-PCR. Cell surface LPA 1 expression was analyzed by flow cytometry. Cell proliferation was analyzed using a cell-counting kit. Production of interleukin 6 (IL-6), vascular endothelial growth factor (VEGF), chemokine (C-C motif) ligand 2 (CCL2), metalloproteinase 3 (MMP-3) and chemokine (C-X-C motif) ligand 12 (CXCL12) was measured by enzyme-linked immunosorbent assay. Pseudoemperipolesis was evaluated using a coculture of RA FLSs and T or B cells. Cell motility was examined by scrape motility assay. Expression of adhesion molecules was determined by flow cytometry.

Results: The expression of $L P A_{1}$ mRNA and cell surface $L P A_{1}$ was higher in RA FLSs than in FLSs from osteoarthritis tissue. Stimulation with LPA enhanced the proliferation of RA FLSs and the production of IL-6, VEGF, CCL2 and MMP-3 by FLSs, which were suppressed by an LPA 1 inhibitor (LA-01). Ki16425, another LPA 1 antagonist, also suppressed IL-6 production by LPA-stimulated RA FLSs. However, the production of CXCL12 was not altered by stimulation with LPA. LPA induced the pseudoemperipolesis of T and B cells cocultured with RA FLSs, which was suppressed by LPA inhibition. In addition, LPA enhanced the migration of RA FLSs and expression of vascular cell adhesion molecule and intercellular adhesion molecule on RA FLSs, which were also inhibited by an LPA, antagonist.

Conclusions: Collectively, these results indicate that LPA-LPA, signaling contributes to the activation of RA FLSs.

\section{Introduction}

Rheumatoid arthritis (RA) is a chronic inflammatory disease characterized by synovial hyperplasia with proliferation of fibroblast-like synoviocytes (FLSs), angiogenesis, infiltration of inflammatory cells such as lymphocytes and macrophages, and bone destruction of multiple joints

\footnotetext{
* Correspondence: nanki@med.teikyo-u.ac.jp

${ }^{1}$ Department of Medicine and Rheumatology, Graduate School of Medical and Dental Sciences, Tokyo Medical and Dental University, 1-5-45, Yushima, Bunkyo-ku, Tokyo 113-8519, Japan

${ }^{4}$ Department of Clinical Research Medicine, Teikyo University, 2-11-1, Kaga, Itabashi-ku, Tokyo 173-8605, Japan

Full list of author information is available at the end of the article
}

[1]. FLSs are especially responsible for inflammation through cytokine and chemokine production and are also key cells of the invasive synovium, suggesting that they play a major role in the initiation and perpetuation of the destruction of inflamed joints [2].

Lysophosphatidic acid (LPA) is a bioactive lipid that binds to its specific cell surface $\mathrm{G}$ protein-coupled receptors $\left(\mathrm{LPA}_{1-6}\right)$. LPA is generated via the hydrolysis of lysophosphatidylcholine by a secretory protein, autotaxin (ATX), which exhibits lysophospholipase D activity [3]. ATX was shown to be highly expressed in tumor cells, including neuroblastoma, breast cancer and renal cell carcinoma [4-6]. Moreover, LPA was reported to induce 
the production of interleukin 8 (IL-8) and vascular endothelial growth factor (VEGF) by cancer cells, angiogenesis and cancer growth [7-11].

It has previously been shown that expression of ATX by FLSs in the RA synovium and concentration of ATX in the RA synovial fluid are increased [12]. In addition, $\mathrm{LPA}_{1-3}$ mRNA has been reported to be expressed in RA FLSs, and incubation with LPA induced cell motility and cytokine expression by the FLSs, indicating that LPA may contribute to the pathogenesis of RA by stimulation of FLSs [13,14]. We recently demonstrated that treatment with an LPA receptor $1\left(\mathrm{LPA}_{1}\right)$ antagonist, LA-01, ameliorated murine collagen-induced arthritis, probably via inhibition of inflammatory cell migration, Th17 differentiation and osteoclastogenesis [15].

In this study, we extensively analyzed the stimulatory effects of LPA for RA FLSs, as well as the effects of an $\mathrm{LPA}_{1}$ antagonist, LA-01, against this stimulation.

\section{Methods \\ Specimens}

Synovial tissues were obtained from RA patients $(n=10)$ who fulfilled American College of Rheumatology criteria [16] and from patients with osteoarthritis (OA) $(n=5)$. RA patients were a median (range) of 67 years old (45 to 80 ), and had a disease duration of 14 years (2 to 30 ) and C-reactive protein level of $0.68 \mathrm{mg} / \mathrm{dl}(0.0$ to $2.85)$. Seven patients (70\%) were positive for rheumatoid factor, and seven $(70 \%)$ were positive for anticitrullinated protein antibodies. All patients provided informed consent. The experimental protocol was approved by the ethics committee of the Tokyo Medical and Dental University.

\section{Fibroblast-like synoviocytes}

Synovial tissues from RA patients were minced and incubated with $0.5 \mathrm{mg} / \mathrm{ml}$ collagenase (Sigma-Aldrich, St Louis, MO, USA) for 1 hour at $37^{\circ} \mathrm{C}$, then passed through a metal screen to obtain single-cell suspensions. Harvested cells were plated in cell culture plates and incubated with Dulbecco's modified Eagle's medium (DMEM) (SigmaAldrich) supplemented with $10 \%$ fetal calf serum (FCS) (Sigma-Aldrich). Adherent cells were maintained in the medium as FLSs and were used after five passages in the following experiments [17].

\section{RT-PCR}

Total RNA was prepared from the FLSs of RA tissue $(n=10)$ and OA synovial tissue $(n=5)$, and firststrand cDNA was synthesized. Quantitative real-time RTPCR was performed as described previously [18]. cDNA was amplified with primers for $\mathrm{LPA}_{1}$ (sense, $5^{\prime}$-ACC CAA TAC TCG GAG ACT GAC TGT-3'; antisense, 5'-CGT
CAG GCT GGT GTC AAT GA-3'), LPA 2 (sense, 5' -TCA TCA TGG GCC AGT GCT ACT-3'; antisense, 5'-GTG GGA GCT GAG CTC TTT GC-3'), LPA 3 (sense, 5'-CTT GAC TGC TTC CCT CAC CAA-3'; antisense, 5' -CGC ATC CTC ATG ATT GAC ATG-3'), LPA $_{4}$ (sense, 5' -TCC TCA GTG GCG GTA TTT CAG-3; antisense, 5'-AAG

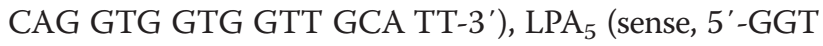
GGT GAG CGT GTA CAT GTG T-3'; antisense, 5' -AGT GGT GCA GTG CGT AG TAG GA-3'), LPA 6 (sense, 5' AGA ACC AAA AGA AAT GCA AAG ATT G-3'; antisense, 5' -ACG GCG GGT GCA CTT C-3') and 18S rRNA (sense, 5'-AAC CAG ACA AAT CGC TCC AC-3'; antisense, 5'-ACT CAA CAC GGG AAA CCT CA-3'). $18 \mathrm{~S}$ rRNA was used as an internal control to standardize the amount of sample mRNA, and the relative expression of real-time PCR products was determined.

\section{Cell surface expression of lysophosphatidic acid receptor 1 on fibroblast-like synoviocytes}

FLSs were stained with anti-LPA 1 monoclonal antibody (mAb) (1G6; LSBio, Seattle, WA, USA) as a first antibody, and phycoerythrin-conjugated anti-mouse immunoglobulin G (IgG) antibody (BioLegend, San Diego, CA, USA) as a second antibody. Mouse IgG2b (BioLegend) was used as an isotype control. Cells were then analyzed by flow cytometry (FACSCalibur; BD Biosciences, San Jose, CA, USA).

\section{Proliferation assay}

FLSs were plated at a density of $2 \times 10^{3}$ cells/well in 96-well flat-bottom plates. Cells were incubated with a selective $\mathrm{LPA}_{1}$ antagonist (LA-01 (0, 1 or $10 \mathrm{nM}$ ); provided by Ono Pharmaceutical, Osaka, Japan) $[15,19]$ for 30 minutes and then stimulated with LPA (Cayman Chemical, Ann Arbor, MI, USA) (0, 1 or $10 \mu \mathrm{M})$ in FCSfree DMEM at $37^{\circ} \mathrm{C}$ for 72 hours. The proliferation of FLSs was measured by using a cell-counting kit with WST-8 (2-(2-methoxy-4-nitrophenyl)-3-(4-nitrophenyl)5-(2,4-disulfophenyl)-2H-tetrazolium, monosodium salt; Dojindo, Kumamoto, Japan) according to the manufacturer's protocol. $\mathrm{LPA}_{1}, \mathrm{LPA}_{2}$ and $\mathrm{LPA}_{3}$ share $50 \%$ to $57 \%$ amino acid identity in humans and comprise the endothelial cell differentiation gene (Edg) family of LPA receptors [20]. The half-maximal inhibitory concentration (IC50) of LA-01 was 0.086, 2.8 and $0.90 \mu \mathrm{mol} / \mathrm{L}$ for $\mathrm{LPA}_{1}, \mathrm{LPA}_{2}$ and $\mathrm{LPA}_{3}$, respectively, which was determined by $\mathrm{LPA}_{1-}$, $\mathrm{LPA}_{2}$ - or $\mathrm{LPA}_{3}$-transfected $\mathrm{CHO}$ cells $[15,19]$. $\mathrm{LPA}_{4-6}$ receptors have been classified into the non-Edg family of LPA receptors and are structurally distant from the Edg family of LPA receptors [20]. The $\mathrm{IC}_{50}$ of LA-01 for $\mathrm{LPA}_{4-6}$ was not determined. Incubation with LA-01 did not affect viability of the FLSs (data not shown). 
B

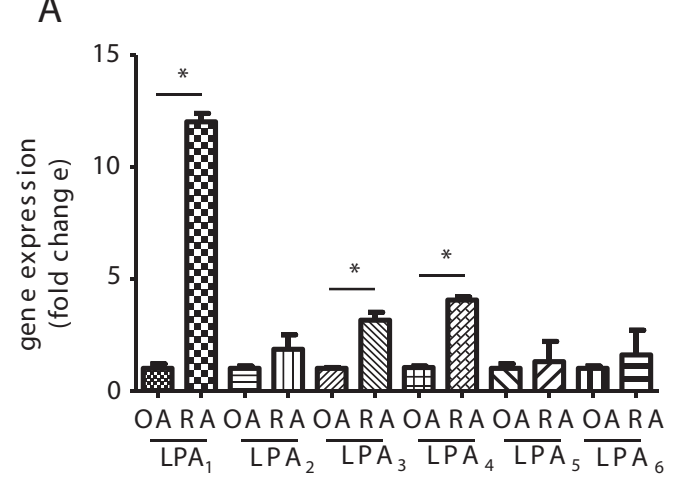

C

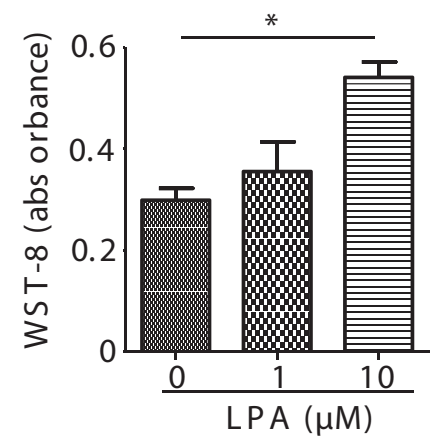

F

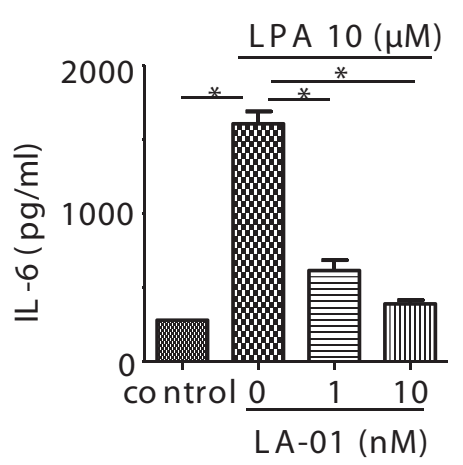

D

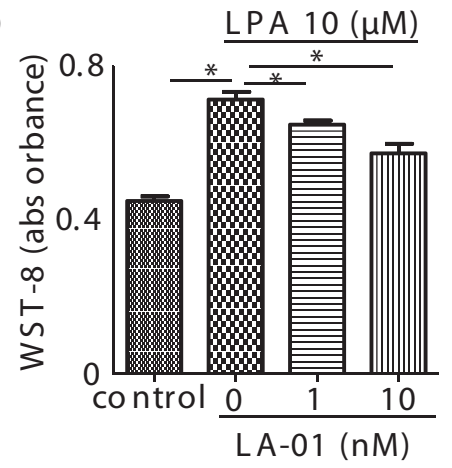

G

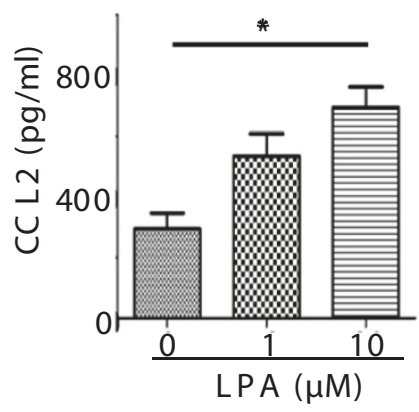

I
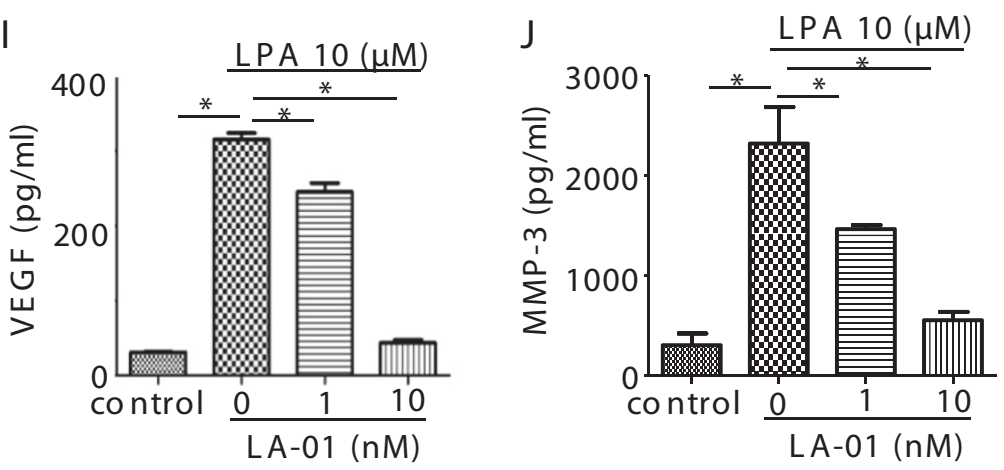

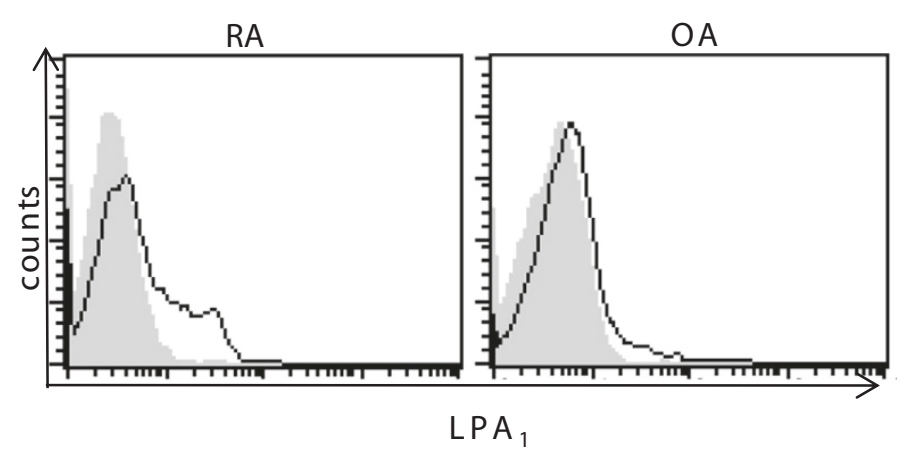

$\mathrm{E}$

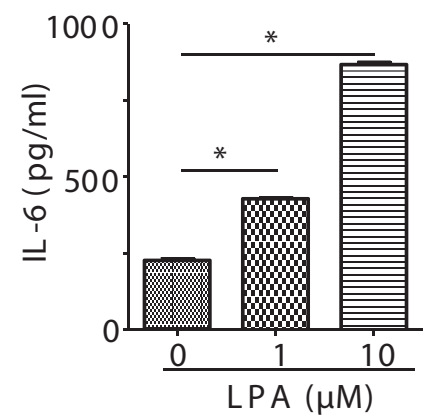

$\mathrm{H}$

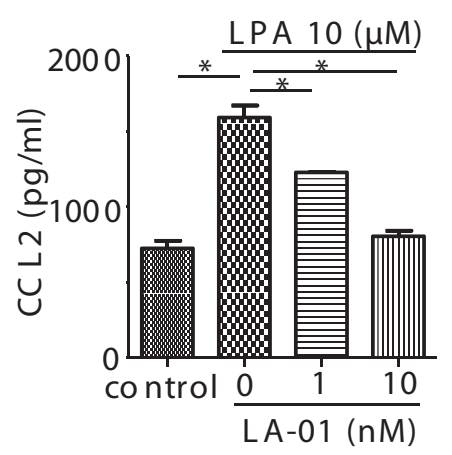

Figure 1 (See legend on next page.)

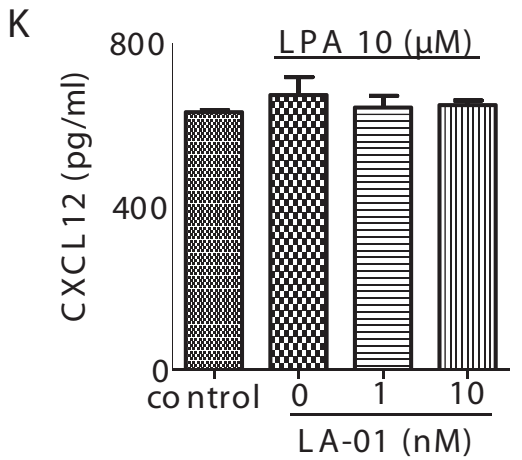


(See figure on previous page.)

Figure 1 Expression of lysophosphatidic acid receptors and the effect of lysophosphatidic acid receptor 1 on proliferation and production of inflammatory mediators in rheumatoid arthritis fibroblast-like synoviocytes. The expression levels of lysophosphatidic acid receptor 1 through $6\left(L P A_{1-6}\right)$ mRNA in fibroblast-like synoviocytes (FLSs) derived from the rheumatoid arthritis (RA) synovium $(n=10)$ were compared to those in FLSs from osteoarthritis $(\mathrm{OA})$ synovium $(n=5)$ by real-time RT-PCR $(\mathbf{A})$. Data were derived from samples from multiple individuals. Data are presented as the mean \pm SEM. ${ }^{*} P<0.05$ for RA vs OA. Cell surface expression of $L_{P A}$ on RA $(n=5)$ and OA $(n=3)$ FLSs was analyzed by flow cytometry (B). Filled histogram (gray): isotype control; open histogram (black line): LPA 1 . Representative histograms are shown. RA FLSs were cultured with lysophosphatidic acid (LPA) for 72 hours (C). FLSs were preincubated with an LPA1 inhibitor, LA-01, for 30 minutes, then stimulated with $10 \mu \mathrm{M}$ LPA for 72 hours (D). Control: no stimulation with LPA. Cell proliferation was measured by using a cell counting kit (C) and (D). RA FLSs were cultured with LPA for 24 hours. Concentrations of interleukin 6 (IL-6) and chemokine (C-C motif) ligand 2 (CCL2) in the culture supernatant were measured by enzyme-linked immunosorbent assay (ELISA) (E) and (G). FLSs were preincubated with LA-01 for 30 minutes, then stimulated with $10 \mu \mathrm{M}$ LPA for 24 hours. Concentrations of IL-6, CCL2, vascular endothelial growth factor (VEGF), matrixmetalloproteinase (MMP-3) and CXCL12 in the culture supernatant were measured by ELISA (F), and $(\mathrm{H})$ through $(\mathbf{K})$. Control: no stimulation with LPA. Data are presented as the means ( \pm SEM) of one of three independent experiments analyzed in triplicate. ${ }^{*} P<0.05$ vs control or LA-01 $0 \mathrm{nM}$ (C) through (K).

\section{Enzyme-linked immunosorbent assay}

RA FLSs were cultured overnight in 96-well plates $\left(2 \times 10^{4}\right.$ cells/well), then incubated with LA-01 $(0,1$ or $10 \mathrm{nM})$ or Ki16425 (2 nM) (Cayman Chemical) 30 minutes before stimulation with LPA $(10 \mu \mathrm{M})$ in FCS-free DMEM at $37^{\circ} \mathrm{C}$ for 24 hours. Protein levels of IL-6, chemokine (C-C motif) ligand 2 (CCL2), VEGF, matrix metalloproteinase 3 (MMP-3) and chemokine (C-X-C motif) ligand 12 (CXCL12) in the culture supernatant were assessed by using ELISA kits (R\&D Systems, Minneapolis, MN, USA) according to the instructions supplied by the manufacturer.

\section{Pseudoemperipolesis}

FLSs were seeded onto 96-well plates $\left(2 \times 10^{4}\right.$ cells/well $)$ and cultured for 48 hours. CD4- and CD8-positive (CD4 ${ }^{+}$ and $\mathrm{CD}^{+}$, respectively) $\mathrm{T}$ cells and $\mathrm{CD}_{1} 9^{+} \mathrm{B}$ cells were purified from human peripheral blood of healthy volunteers by using MACS microbeads ( $>95 \%$ purity; Miltenyi Biotec, Auburn, CA, USA) and added to the FLS-cultured wells $\left(1 \times 10^{5}\right.$ cells/well). The cells were treated with LA$01(0,1$ or $10 \mathrm{nM})$ for 30 minutes, followed by stimulation with LPA $(10 \mu \mathrm{M})$ in FCS-free DMEM. After 12 hours, the wells were washed three times with medium. Pseudoemperipolesis was assessed by counting the number of cells beneath FLSs in three independent fields under a microscope.

\section{Scrape motility assay}

RA FLSs were plated at a density of $1 \times 10^{5}$ cells $/ \mathrm{ml}$ in 12 -well plates in DMEM with $10 \%$ FCS. After overnight incubation, FLSs was washed twice with FCS-free medium. The tip of a plastic pipette was drawn across the center of the well to produce a scraped area. Culture wells were washed twice with PBS, and free cells were removed. After pretreatment with LA-01 (0, 1 or $10 \mathrm{nM})$ for 30 minutes, cells were incubated with LPA $(10 \mu \mathrm{M})$ in FCS-free DMEM. A cell-free area was measured by using ImageJ software (National Institutes of Health, Bethesda,
MD, USA) at 0 and 48 hours, and the ratio was then calculated (cell-free area at 48 hours per cell-free area at 0 hours).

\section{Expression of vascular cell adhesion molecule and intercellular adhesion molecule on RA fibroblast-like synoviocytes}

FLSs were stimulated with LPA $(10 \mu \mathrm{M}) 30$ minutes after adding LA-01 (0, 1 or $10 \mathrm{nM})$ in FCS-free DMEM at $37^{\circ} \mathrm{C}$ for 12 hours. Cells were stained with allophycocyaninconjugated $\mathrm{mAb}$ against vascular cell adhesion molecule (anti-VCAM, clone STA; BioLegend) or phycoerythrinconjugated $\mathrm{mAb}$ against intracellular adhesion molecule (anti-ICAM, clone HA58; eBioscience, San Diego, CA, USA). Allophycocyanin- or phycoerythrin-conjugated mouse IgG1 (BioLegend) was used as an isotype control. Cells were then analyzed by flow cytometry (Accuri C6 Flow Cytometer; BD Biosciences).

\section{Statistical analysis}

Data are expressed as mean \pm standard error of the mean (SEM). The comparison of the data from the two groups was conducted by using Student's $t$-test. $P$-values less than 0.05 were considered significant.

\section{Results}

Expression of lysophosphatidic acid receptors in RA fibroblast-like synoviocytes

The expression of $\mathrm{LPA}_{1-6}$ mRNA in FLSs from RA and OA patients was analyzed by quantitative real-time RTPCR. The expression of $\mathrm{LPA}_{1}$ mRNA in RA FLSs was significantly higher than that in OA FLSs (Figure 1A). The expression of $\mathrm{LPA}_{3}$ and $\mathrm{LPA}_{4}$ was also significantly higher in RA FLSs than that in OA FLSs, although the ratios of $\mathrm{LPA}_{3}$ and $\mathrm{LPA}_{4}$ expression in RA FLSs to OA FLSs were smaller than those of $\mathrm{LPA}_{1}$ expression. Cell surface $\mathrm{LPA}_{1}$ expression was analyzed by flow cytometry. RA FLSs were expressed $\mathrm{LPA}_{1}$ on the cell surface, and 


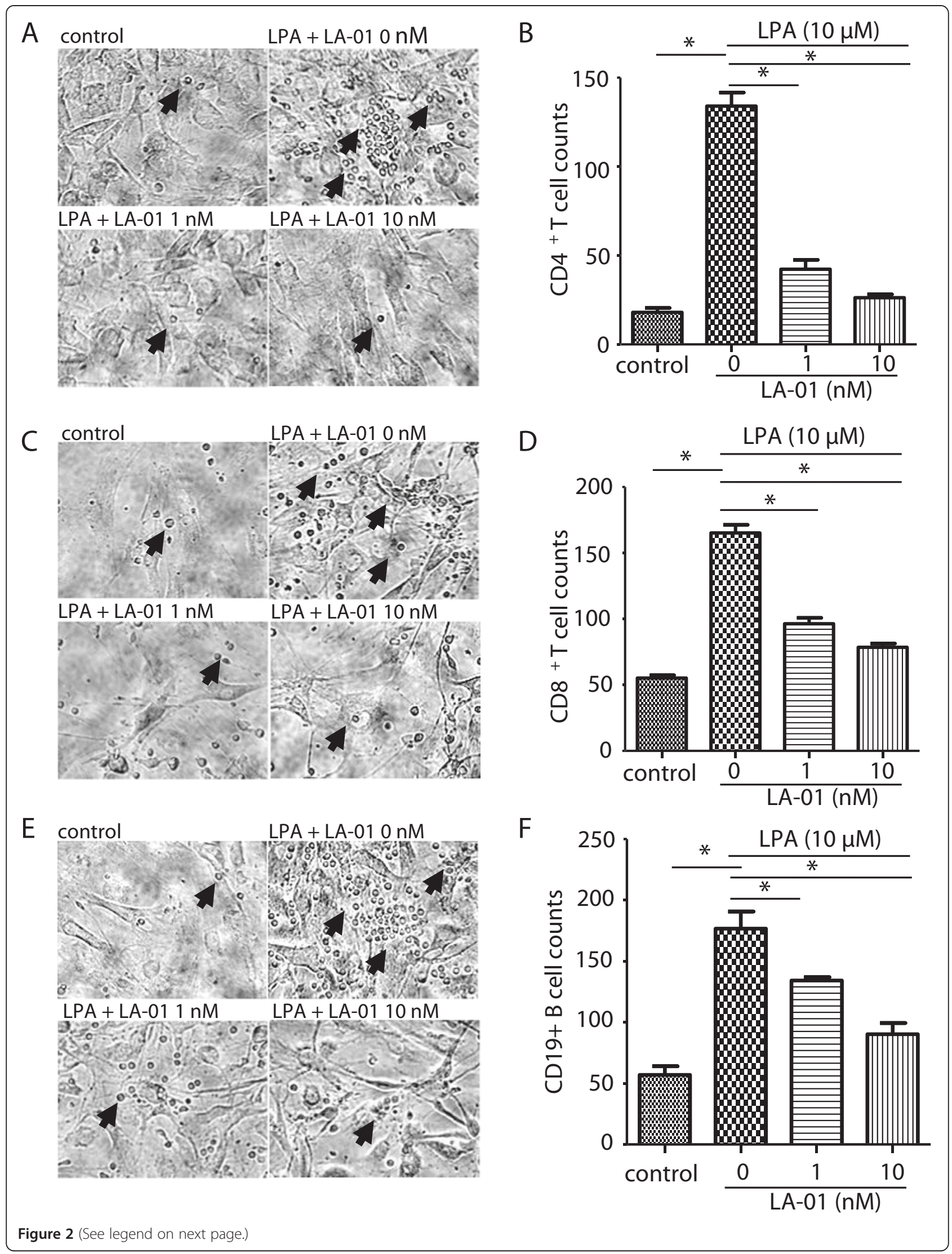


(See figure on previous page.)

Figure 2 Effect of lysophosphatidic acid receptor 1 on pseudoemperipolesis and migration of rheumatoid arthritis fibroblast-like synoviocytes. After preincubation of cocultured rheumatoid arthritis (RA) fibroblast-like synoviocytes (FLSs) and CD4 ${ }^{+} \mathrm{T}$ cells (A) and (B) or $\mathrm{CD}^{+} \mathrm{T}$ cells $(\mathbf{C})$ and $(\mathbf{D})$ or $C D 19^{+} \mathrm{B}$ cells $(\mathbf{E})$ and $(\mathbf{F})$ with a lysophosphatidic acid (LPA) receptor 1 inhibitor (LA-01; 0, 1 or 10 nM) for 30 minutes, the cells were stimulated with $10 \mu \mathrm{M}$ LPA for 12 hours. Control: no stimulation with LPA. After the cells were washed, the number of lymphocytes beneath FLSs was counted. Representative photomicrographs of three independent experiments are shown (A, C and E). Arrows indicate the lymphocytes beneath FLSs. Original magnification, $\times 200$. Data on the number of lymphocytes beneath FLSs are presented as one of three independent experiments analyzed in triplicate $\mathbf{( B ,} \mathbf{D}$, and $\mathbf{F})$. Data are presented as the mean \pm SEM. ${ }^{*} P<0.05$ vs control or LA-01 0 nM (B, D, F).

the expression level was substantially higher than that of OA FLSs (Figure 1B).

\section{Lysophosphatidic acid receptor 1 inhibitor suppressed lysophosphatidic acid-induced proliferation and cytokine production in RA fibroblast-like synoviocytes}

We analyzed the effects of LPA on the proliferation and production of inflammatory mediators by RA FLSs. Stimulation with LPA dose-dependently induced the proliferation of FLSs (Figure 1C). LPA stimulation also induced the production of IL- 6 and CCL2 from FLSs in a dose-dependent manner (Figures $1 \mathrm{E}$ and $1 \mathrm{G}$ ), which supports a previous report that LPA upregulated IL-6 mRNA expression by RA FLSs [18]. Stimulation with LPA also induced the production of VEGF and MMP-3 by RA FLSs in vitro (Figures $1 \mathrm{I}$ and $1 \mathrm{~J})$.

Next, we analyzed the effect of an $\mathrm{LPA}_{1}$ inhibitor on LPA stimulation for RA FLSs. Enhanced cell proliferation by $10 \mu \mathrm{M}$ LPA was significantly suppressed by LA-01, the $\mathrm{LPA}_{1}$-selective antagonist (Figure 1D). The treatment with LA-01 significantly reduced the production of IL-6, CCL2, VEGF and MMP-3 by LPA-stimulated RA FLSs (Figures $1 \mathrm{~F}$ and $1 \mathrm{H}$ through $1 \mathrm{~J}$ ). In contrast, the production of CXCL12 by RA FLSs was not altered by stimulation with LPA (Figure 1K). We used Ki16425, another $\mathrm{LPA}_{1}$ antagonist, to confirm the effects of $\mathrm{LPA}_{1}$ inhibition on IL-6 production from LPA-stimulated RA FLSs. Incubation with Ki16425 suppressed IL-6 production from LPA-stimulated RA FLSs as well as LA-01 (IL-6 concentrations: vehicle $=299.413 \pm 28.084 \mathrm{pg} / \mathrm{ml}$; Ki16425 $=116.785 \pm 11.162 \mathrm{pg} / \mathrm{ml}(P<0.05$ vs vehicle $)$; LA-01 $=145.715 \pm 15.921 \mathrm{pg} / \mathrm{ml}(P<0.05$ vs vehicle $))$. These results suggest that LPA-LPA 1 signaling plays important roles in proliferation and cytokine production of RA FLSs in vitro.

\section{LPA-LPA 1 signaling promoted pseudoemperipolesis}

RA FLSs have been shown to promote the spontaneous migration of leukocytes beneath them, a process termed pseudoemperipolesis [21]. We examined the effect of LPA on pseudoemperipolesis. Stimulation with $10 \mu \mathrm{M}$ LPA significantly increased the number of $\mathrm{CD} 4^{+}$and $\mathrm{CD}^{+} \mathrm{T}$ cells, as well as $\mathrm{CD} 19^{+} \mathrm{B}$ cells, beneath RA FLSs (Figures 2A to 2F). Moreover, incubation with LA-01 suppressed the LPA-enhanced pseudoemperipolesis of
$\mathrm{CD}^{+}$and $\mathrm{CD}^{+} \mathrm{T}$ and $\mathrm{CD} 19^{+} \mathrm{B}$ cells (Figures 2A through $2 \mathrm{~F}$ ), suggesting that interaction of LPA and $\mathrm{LPA}_{1}$ promotes pseudoemperipolesis of leukocytes.

\section{LPA-LPA 1 signaling promoted cell motility of RA fibroblast-like synoviocytes}

We also analyzed the effect of $\mathrm{LPA}_{1}$ on RA FLS migration by scrape motility assay. Incubation with $10 \mu \mathrm{M}$ LPA significantly decreased the cell-free area, indicating that LPA induced cell migration in vitro (Figures $3 \mathrm{~A}$ and $3 \mathrm{~B}$ ), as reported previously [22]. In addition, LA-01 significantly increased the cell-free area of RA FLSs (Figures 3A and 3B), suggesting that $\mathrm{LPA}-\mathrm{LPA}_{1}$ signaling also contributes to the promotion of RA FLS motility.

\section{LPA-LPA 1 signaling induced adhesion molecule expression on RA fibroblast-like synoviocytes}

It has been reported that signaling from VCAM and ICAM in RA FLSs supports pseudoemperipolesis [21]. Therefore, we next analyzed the expression of VCAM and ICAM on RA FLSs by flow cytometry. We found that stimulation with $10 \mu \mathrm{M}$ LPA induced the expression of VCAM and ICAM on RA FLSs (Figure 4). Moreover, LA-01 decreased the expression of VCAM and ICAM induced by LPA on RA FLSs (Figure 4). However, the expression of E-selectin on RA FLSs was not altered by LPA simulation (data not shown).

\section{Discussion}

In this study, we found that $\mathrm{LPA}_{1}$ was highly expressed in RA FLSs. LPA stimulated RA FLSs to enhance proliferation, production of inflammatory mediators, pseudoemperipolesis, migration and the expression of adhesion molecules, which are attributable to signaling through $\mathrm{LPA}_{1}$.

RA FLSs express inflammatory cytokines, chemokines and matrix-degrading enzymes, which contribute to the pathogenesis of RA. LPA has been reported to induce IL-6 mRNA expression on RA FLSs, as well as cell motility [13]. However, the corresponding LPA receptor on RA FLSs has not been identified. We show that LPA augmented IL-6, CCL2, VEGF and MMP-3 production by RA FLSs. Moreover, the LPA-induced production of the inflammatory mediators was inhibited by a $\mathrm{LPA}_{1}$ selective inhibitor. Therefore, the LPA-LPA 1 cascade plays 

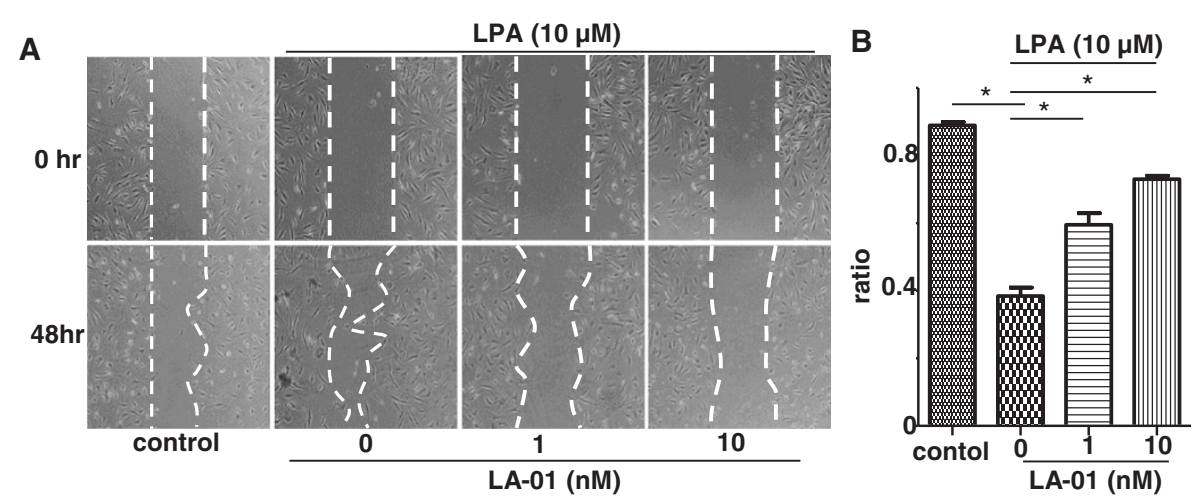

Figure 3 The effect of lysophosphatidic acid receptor 1 on the migration of rheumatoid arthritis fibroblast-like synoviocytes. A scraped cell-free area was created on cultured RA FLSs. After preincubation with a lysophosphatidic acid (LPA) receptor 1 inhibitor (LA-01; 0, 1 or 10 nM) for 30 minutes, cells were stimulated with $10 \mu \mathrm{M}$ LPA for 48 hours. Control: no stimulation with LPA. (A) Representative photomicrographs of three independent experiments are shown. Original magnification, $\times 40$. (B) The cell-free area was assessed, and a ratio (cell-free area in 48 hours to cell-free area in 0 hours) was defined. Data are presented as the means ( \pm SEM) of one of three independent experiments analyzed in triplicate. ${ }^{*} P<0.05$ vs control or LA-01 $0 \mathrm{nM}$. Upper dashed line indicates the cells are stimulated with LPA $10 \mathrm{uM}$, and lower dashed line indicates LA-01 is added with indicated concentration.

an important role in cytokine, chemokine and matrixdegrading enzyme production by RA FLSs. Although $\mathrm{IC}_{50}$ of LA-01 was $86 \mathrm{nM}$, which was determined by using $\mathrm{LPA}_{1}$-transfected $\mathrm{CHO}$ cells, $10 \mathrm{nM}$ LA-01 significantly inhibited stimulation of LPA in RA FLSs. The $\mathrm{IC}_{50}$ may be dependent on cell type or on the expression level of $\mathrm{LPA}_{1}$.
Pseudoemperipolesis contributes to the chronic inflammation induced by lymphocyte recruitment in the inflamed joints and protects lymphocytes from apoptosis $[21,23,24]$. We show that LPA enhanced the pseudoemperipolesis of $\mathrm{T}$ and $\mathrm{B}$ cells, which is also attributable to $\mathrm{LPA}_{1}$. It has been reported that stimulation with CXCL12 and signaling from VCAM and ICAM in RA

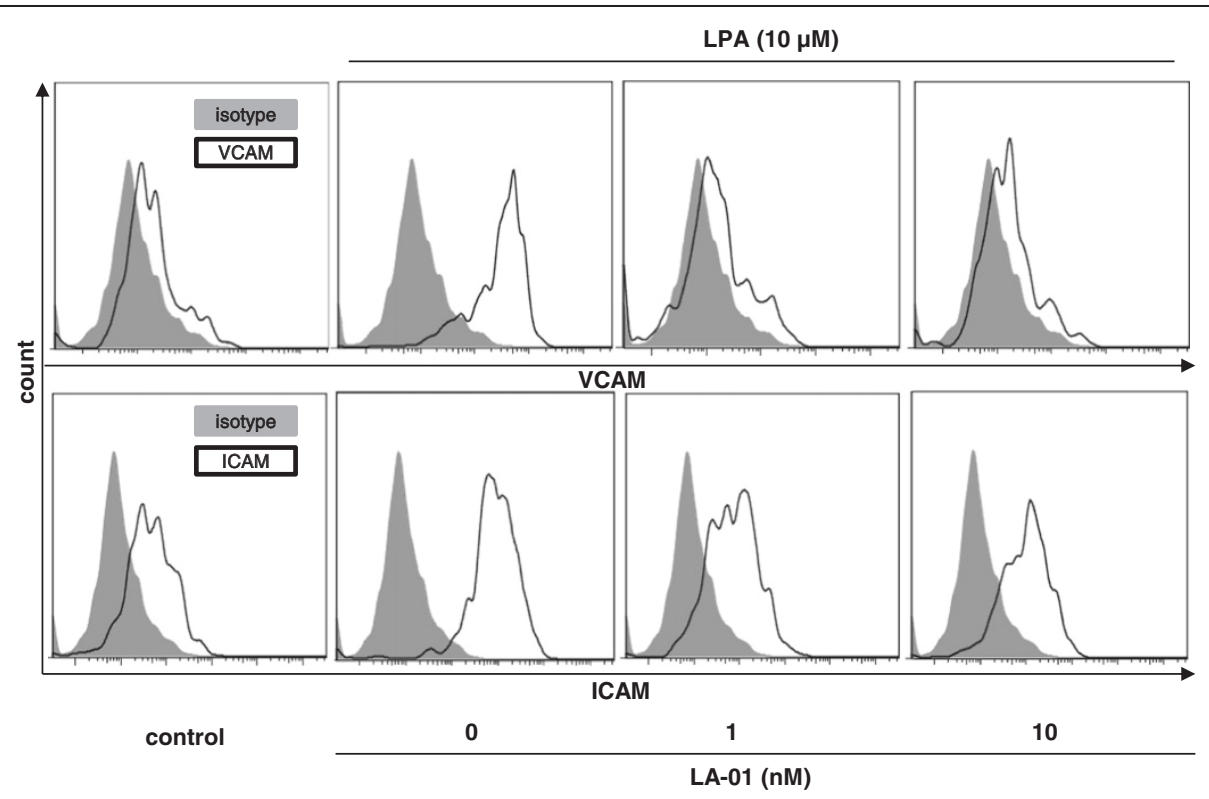

Figure 4 The effect of lysophosphatidic acid receptor 1 on the expression of adhesion molecules on fibroblast-like synoviocytes. Rheumatoid arthritis (RA) fibroblast-like synoviocytes (FLSS) were pretreated with a lysophosphatidic acid (LPA) receptor 1 inhibitor (LA-01; 0, 1 or $10 \mathrm{nM}$ ) for 30 minutes, then the cells were stimulated with $10 \mu \mathrm{M}$ LPA for 12 hours. Cells were stained with allophycocyanin-conjugated monoclonal antibody (mAb) against vascular cell adhesion molecule (anti-VCAM) or phycoerythrin-conjugated mAb against intercellular adhesion molecule (anti-ICAM). Allophycocyanin- or phycoerythrin-conjugated mouse immunoglobulin G1 (lgG1) was used as a control. The expression of VCAM and ICAM on FLSs was analyzed by flow cytometry. Filled histogram (gray): isotype control; open histogram (black line): VCAM or ICAM. 
FLSs support pseudoemperipolesis [21]. Our results indicate that LPA upregulated the expression of VCAM and ICAM on RA FLSs, which was blocked by the LPA antagonist. Thus, LPA may enhance pseudoemperipolesis via the upregulation of VCAM and ICAM expression on RA FLSs through $\mathrm{LPA}_{1}$. Interestingly, CXCL12 production by RA FLSs was not altered by LPA simulation. Stimulation of lymphocytes by LPA via $\mathrm{LPA}_{1}$ may also contribute to the enhanced pseudoemperipolesis. In this regard, it has been reported that LPA induced chemokinesis in $\mathrm{T}$ cells [25] and lymphocyte transmigration through high endothelial venules [26,27]. Further studies are needed to clarify the effects of LPA-LPA 1 signaling for the lymphocytes on pseudoemperipolesis.

The hyperplastic rheumatoid pannus is characterized by an overabundance of FLSs [2]. This cellular excess stems largely from an imbalance between the proliferation and apoptosis of FLSs [2]. The migration of RA FLSs may also contribute to pannus formation [2]. Our results show that LPA induced the proliferation and migration of FLSs, which was inhibited by the $\mathrm{LPA}_{1}$ antagonist. Moreover, in a recent study, researchers reported that LPA suppressed tumor necrosis factor-induced apoptosis on RA FLSs via $\mathrm{LPA}_{1}$ [28]. Therefore, it is suggested that the LPA-LPA $A_{1}$ signaling also contributed to the cellular excess and migration of FLSs in the RA synovium.

In this study, we show that there are important roles of LPA-LPA 1 signaling on RA FLS stimulation. However, the effects of LPA signals via $\mathrm{LPA}_{2-6}$ remain unclear, although RA FLSs also expressed $\mathrm{LPA}_{2-6}$. Further studies are warranted to elucidate the roles of $\mathrm{LPA}_{2-6}$ in LPA stimulation of FLSs by using each of the LPA receptor-specific antagonists or FLSs from each LPA receptor-deficient mouse.

It was shown that conditional genetic ablation of ATX, which generates LPA via hydrolysis of lysophosphatidylcholine, in mesenchymal cells resulted in disease attenuation in animal models of arthritis [12]. We have also found that $\mathrm{LPA}_{1}$ is essential for the development of arthritis in collagen-induced arthritis [15]. The ATX-LPA$\mathrm{LPA}_{1}$ axis may play an important role in the development of arthritis.

\section{Conclusion}

Our study suggests that LPA-LPA 1 signaling in FLSs may contribute to the pathogenesis of RA by inducing proliferation, production of inflammatory mediators, pseudoemperipolesis and migration on RA FLSs. Thus, $\mathrm{LPA}_{1}$ could be a promising therapeutic target for RA.

\footnotetext{
Abbreviations

ATX: Autotaxin; CCL2: Chemokine (C-C motif) ligand 2; CXCL12: Chemokine (C-X-C motif) ligand 12; DMEM: Dulbecco's modified Eagle's medium; Edg: Endothelial cell differentiation gene; ELISA: Enzyme-linked
}

immunosorbent assay; FCS: Fetal calf serum; FLS: Fibroblast-like synoviocyte; ICAM: Intercellular adhesion molecule; IL: Interleukin; LPA: Lysophosphatidic acid; mAb: Monoclonal antibody; MMP-3: Metalloproteinase 3; OA: Osteoarthritis; RA: Rheumatoid arthritis; SEM: Standard error of the mean; VCAM: Vascular cell adhesion molecule; VEGF: Vascular endothelial growth factor.

\section{Competing interests}

The authors declare that they have no competing interests.

\section{Authors' contributions}

YM participated in the design of the study, carried out the experiments and statistical analysis and drafted the manuscript. CM and CS assisted in carrying out the experiments and with manuscript preparation. YI assisted in data interpretation and manuscript preparation. WY and KS collected the clinical materials and assisted in data interpretation and manuscript preparation. $\mathrm{MH}, \mathrm{MM}, \mathrm{NM}$ and TN conceived of the study, participated in its design and coordination, and helped to draft the manuscript. All authors read and approved the final manuscript.

\section{Acknowledgements}

We thank Prof. Timothy J Wright (Otsuma Women's University, Tokyo, Japan) for his helpful advice and for improving the readability of this manuscript. This work was supported in part by the Japanese Ministry of Education, Global Center of Excellence (GCOE) Program, International Research Center for Molecular Science in Tooth and Bone Diseases, and Takeda Science Foundation.

\section{Author details}

${ }^{1}$ Department of Medicine and Rheumatology, Graduate School of Medical and Dental Sciences, Tokyo Medical and Dental University, 1-5-45, Yushima, Bunkyo-ku, Tokyo 113-8519, Japan. ${ }^{2}$ Department of Dermatology, Tokyo Medical University, 6-7-1, Nishi-Shinjuku, Shinjuku-ku, Tokyo 160-0023, Japan. ${ }^{3}$ Department of Molecular Biology, School of Medicine, University of Occupational and Environmental Health, 1-1 Iseigaoka, Yahatanishi-ku, Kitakyushu, Fukuoka 807-8555, Japan. ${ }^{4}$ Department of Clinical Research Medicine, Teikyo University, 2-11-1, Kaga, Itabashi-ku, Tokyo 173-8605, Japan. ${ }^{5}$ Sonoda Joint Replacement and Sports Medical Center, 1-21-10, Hogima, Adachi-ku, Tokyo 121-0064, Japan. ${ }^{6}$ Department of Pharmacovigilance, Graduate School of Medical and Dental Sciences, Tokyo Medical and Dental University, 1-5-45, Yushima, Bunkyo-ku, Tokyo 113-8519, Japan. ${ }^{7}$ Interdisciplinary Program for Biomedical Sciences, Osaka University, 2-2, Yamada-oka, Suita, Osaka 565-0871, Japan.

Received: 11 April 2014 Accepted: 22 September 2014

Published online: 02 October 2014

\section{References}

1. Kinne RW, Bräuer R, Stuhlmüller B, Palombo-Kinne E, Burmester GR: Macrophages in rheumatoid arthritis. Arthritis Res 2000, 2:189-202.

2. Bottini N, Firestein GS: Duality of fibroblast-like synoviocytes in RA: passive responders and imprinted aggressors. Nat Rev Rheumatol 2013, 9:24-33.

3. Aoki J: Mechanisms of lysophosphatidic acid production. Semin Cell Dev Biol 2004, 15:477-489.

4. Kawagoe $H$, Stracke ML, Nakamura H, Sano K: Expression and transcriptional regulation of the PD-la/autotaxin gene in neuroblastoma. Cancer Res 1997, 57:2516-2521.

5. Yang SY, Lee J, Park CG, Kim S, Hong S, Chung HC, Min SK, Han JW, Lee HW, Lee HY: Expression of autotaxin (NPP-2) is closely linked to invasiveness of breast cancer cells. Clin Exp Metastasis 2002, 19:603-608.

6. Stassar MJ, Devitt G, Brosius M, Rinnab L, Prang J, Schradin T, Simon J, Petersen S, Kopp-Schneider A, Zöller M: Identification of human renal cell carcinoma associated genes by suppression subtractive hybridization. Br J Cancer 2001, 85:1372-1382.

7. Umezu-Goto M, Kishi Y, Taira A, Hama K, Dohmae N, Takio K, Yamori T, Mills GB, Inoue K, Aoki J, Arai H: Autotaxin has lysophospholipase D activity leading to tumor cell growth and motility by lysophosphatidic acid production. J Cell Biol 2002, 158:227-233.

8. Liu S, Umezu-Goto M, Murph M, Lu Y, Liu W, Zhang F, Yu S, Stephens LC, Cui X, Murrow G, Coombes K, Muller W, Hung MC, Perou CM, Lee AV, Fang X, Milles GB: Expression of autotaxin and lysophosphatidic acid receptors 
increases mammary tumorigenesis, invasion, and metastases. Cancer Cell 2009, 15:539-550. A published erratum appears in Cancer Cell 2009, 16:172.

9. Masuda A, Nakamura K, Izutsu K, Igarashi K, Ohkawa R, Jona M, Higashi K, Yokota H, Okudaira S, Kishimoto T, Watanabe T, Koike Y, Ikeda H, Kozai Y, Kurokawa M, Aoki J, Yatomi Y: Serum autotaxin measurement in haematological malignancies: a promising marker for follicular lymphoma. Br J Haematol 2008, 143:60-70.

10. Schleicher SM, Thotala DK, Linkous AG, Hu R, Leahy KM, Yazlovitskaya EM, Hallahan DE: Autotaxin and LPA receptors represent potential molecular targets for the radiosensitization of murine glioma through effects on tumor vasculature. PLoS One 2011, 6:e22182.

11. Houben AJ, Moolenaar WH: Autotaxin and LPA receptor signaling in cancer. Cancer Metastasis Rev 2011, 30:557-565.

12. Nikitopoulou I, Oikonomou N, Karouzakis E, Sevastou I, NikolaidouKatsaridou N, Zhao Z, Mersinias V, Armaka M, Xu Y, Masu M, Milles GB, Gay $S$, Kollias G, Aidinis $V$ : Autotaxin expression from synovial fibroblasts is essential for the pathogenesis of modeled arthritis. J Exp Med 2012, 209:925-933.

13. Kehlen A, Lauterbach $R$, Santos AN, Thiele K, Kabisch U, Weber E, Riemann D, Langner J: IL-1 $\beta$ - and IL-4-induced down-regulation of autotaxin mRNA and PC-1 in fibroblast-like synoviocytes of patients with rheumatoid arthritis (RA). Clin Exp Immunol 2001, 123:147-154.

14. Bourgoin SG, Zhao C: Autotaxin and lysophospholipids in rheumatoid arthritis. Curr Opin Investig Drugs 2010, 11:515-526.

15. Miyabe Y, Miyabe C, Iwai Y, Takayasu A, Fukuda S, Yokoyama W, Nagai J, Jona M, Tokuhara Y, Ohkawa R, Albers HM, Ovaa H, Aoki J, Chun J, Yatomi Y, Ueda H, Miyasaka M, Miyasaka N, Nanki T: Necessity of lysophosphatidic acid receptor 1 for development of arthritis. Arthritis Rheum 2013, 65:2037-2047

16. Cader MZ, Filer A, Hazlehurst J, de Pablo P, Buckley CD, Raza K Performance of the 2010 ACR/EULAR criteria for rheumatoid arthritis: comparison with 1987 ACR criteria in a very early synovitis cohort. Ann Rheum Dis 2011, 70:949-955.

17. Kaneko K, Miyabe Y, Takayasu A, Fukuda S, Miyabe C, Ebisawa M, Yokoyama W, Watanabe K, Imai T, Muramoto K, Terashima Y, Sugihara T, Matsushima K, Miyasaka N, Nanki T: Chemerin activates fibroblast-like synoviocytes in patients with rheumatoid arthritis. Arthritis Res Ther 2011, 13:R158.

18. Watanabe K, Penfold ME, Matsuda A, Ohyanagi N, Kaneko K, Miyabe Y, Matsumoto K, Schall TJ, Miyasaka N, Nanki T: Pathogenic role of CXCR7 in rheumatoid arthritis. Arthritis Rheum 2010, 62:3211-3220.

19. Tanaka M, Nakaide S, Takaoka Y: Compounds having lysophosphatidic acid receptor antagonism and uses thereof. Patent Version Number: WO/2005/058790 (2005-06-30) [http://patentscope.wipo.int/search/en/ WO2005058790] (accessed 9 October 2014).

20. Ishii S, Noguchi K, Yanagida K: Non-Edg family lysophosphatidic acid (LPA) receptors. Prostaglandins Other Lipid Mediat 2009, 89:57-65.

21. Bradfield PF, Amft N, Vernon-Wilson E, Exley AE, Parsonage G, Rainger GE, Nash GB, Thomas AM, Simmons DL, Salmon M, Buckley CD: Rheumatoid fibroblast-like synoviocytes overexpress the chemokine stromal cellderived factor 1 (CXCL12), which supports distinct patterns and rates of CD4+ and CD8+ T cell migration within synovial tissue. Arthritis Rheum 2003, 48:2472-2482

22. Zhao C, Fernandes MJ, Prestwich GD, Turgeon M, Di Battista J, Clair T, Poubelle PE, Bourgoin SG: Regulation of lysophosphatidic acid receptor expression and function in human synoviocytes: implications for rheumatoid arthritis? Mol Pharmacol 2008, 73:587-600

23. Burger JA, Tsukada N, Burger M, Zvaifler NJ, Dell'Aquila M, Kipps TJ: Blood-derived nurse-like cells protect chronic lymphocytic leukemia B cells from spontaneous apoptosis through stromal cell-derived factor-1. Blood 2000, 96:2655-2663.

24. Burger JA, Zvaifler NJ, Tsukada N, Firestein GS, Kipps TJ: Fibroblast-like synoviocytes support B-cell pseudoemperipolesis via a stromal cell-derived factor-1- and CD106 (VCAM-1) -dependent mechanism. J Clin Invest 2001, 107:305-315.

25. Kanda H, Newton R, Klein R, Morita Y, Gunn MD, Rosen SD: Autotaxin, an ectoenzyme that produces lysophosphatidic acid, promotes the entry of lymphocytes into secondary lymphoid organs. Nat Immunol 2008, 9:415-423.

26. Zhang Y, Chen YC, Krummel MF, Rosen SD: Autotaxin through lysophosphatidic acid stimulates polarization, motility, and transendothelial migration of naive T cells. J Immunol 2012, 189:3914-3924.
27. Bai Z, Cai L, Umemoto E, Takeda A, Tohya K, Komai Y, Veeraveedu PT, Hata E, Sugiura Y, Kubo A, Suematsu M, Hayasaka H, Okudaira S, Aoki J, Tanaka T, Albers HM, Ovaa H, Miyasaka M: Constitutive lymphocyte transmigration across the basal lamina of high endothelial venules is regulated by the autotaxin/lysophosphatidic acid axis. J Immunol 2013, 190:2036-2048.

28. Orosa B, González A, Mera A, Gómez-Reino JJ, Conde C: Lysophosphatidic acid receptor 1 suppression sensitizes rheumatoid fibroblast-like synoviocytes to tumor necrosis factor-induced apoptosis. Arthritis Rheum 2012, 64:2460-2470.

\section{doi:10.1186/s13075-014-0461-9}

Cite this article as: Miyabe et al.: Activation of fibroblast-like synoviocytes derived from rheumatoid arthritis via lysophosphatidic acid-lysophosphatidic acid receptor 1 cascade. Arthritis Research \& Therapy 2014 16:461.

\section{Submit your next manuscript to BioMed Central and take full advantage of:}

- Convenient online submission

- Thorough peer review

- No space constraints or color figure charges

- Immediate publication on acceptance

- Inclusion in PubMed, CAS, Scopus and Google Scholar

- Research which is freely available for redistribution

Submit your manuscript at www.biomedcentral.com/submit
C) Biomed Central 